\title{
ACTUALIDAD POLÍTICA Y CONSTITUCIONAL BELGA (2007-2008): APUNTES PARA ENTENDER UNA CRISIS
}

\author{
ÁNGEL J. SÁNCHEZ NAVARRO \\ Profesor Titular de Derecho Constitucional \\ Universidad Complutense de Madrid
}

SUMARIO

I. Introducción

II. El "terreno de juego": rasgos definitorios del régimen constitucional belga

III. Los «jugadores": el sistema de partidos y la necesaria búsqueda de coaliciones

IV. Apuntes sobre una crisis

\section{INTRODUCCIÓN}

En los últimos doce meses, los medios de comunicación españoles se han hecho eco de diversas cuestiones relativas a la actualidad política e institucional belga, resaltando sus dificultades. Así, en primer lugar, y tras las elecciones legislativas celebradas el 10 de junio de 2007, la opinión pública española supo de las dificultades existentes para la formación de un Gobierno capaz de asegurar una mayoría parlamentaria: hicieron falta nueve meses para lograrlo, y desde el principio su solidez suscitó serias dudas ${ }^{1}$. Por eso, tampoco extraño excesivamente el hecho de que, apenas cuatro meses más tarde, en julio de 2008, se hiciera pública la renuncia del Primer Minis-

1 El acuerdo para formar un Gobierno, formado por cinco partidos y presidido por el líder democristiano flamenco Yves Leterme, se logró el 18 de marzo de 2008. Ya entonces, los periódicos señalaban que el acuerdo de gobierno adolecía de fragilidad y "no entra en las cuestiones que dieron lugar a la crisis", por lo que "la próxima crisis ya está prevista para el verano, porque el acuerdo deja para julio el gran debate, la reforma del Estado" (vide El País, ABC y El Mundo, 19 de marzo de 2008). 
tro $^{2}$. Una renuncia que, además, no fue aceptada por el Monarca Alberto II, lo que parece augurar nuevos acontecimientos.

Todas estas noticias suscitan, sin duda, muchas preguntas sobre el funcionamiento del régimen político de Bélgica, un Estado federal organizado como Monarquía parlamentaria. Pero cuyo funcionamiento se enfrenta a dificultades de naturaleza absolutamente excepcional, por comparación con las que registran otros Estados federales, y otras Monarquías parlamentarias.

Así las cosas, estas páginas pretenden presentar, con inevitable brevedad, algunos datos que, permitiendo conocer mejor las características del régimen constitucional belga, hagan posible también mejorar la comprensión de la naturaleza y alcance de tales dificultades. A tal efecto, comenzaremos por exponer algunas de sus reglas básicas de funcionamiento, reglas que definen un "terreno de juego" político e institucional (II). Dentro del mismo — vale decir: conforme a tales reglas - diversos actores políticos, agrupados en torno a partidos políticos, aparecen como los protagonistas o "jugadores" (III). Como en cualquier otro sistema, tales jugadores persiguen objetivos propios, adoptando a tal fin distintas estrategias que, lógicamente, se enfrentan, lo que da lugar a los principales debates o dificultades. Dificultades que, como trataremos de subrayar, presentan en el caso belga rasgos particulares (IV).

\section{EL “TERRENO DE JUEGO»: RASGOS DEFINITORIOS DEL RÉGIMEN CONSTITUCIONAL BELGA}

Obviamente, el alcance limitado de estas páginas excluye cualquier pretensión de realizar una exposición mínimamente detallada de las características del régimen constitucional belga. No sería posible, ni tampoco deseable, existiendo por lo demás trabajos específicamente dirigidos a tal fin, a los que puede remitirse cualquier lector interesado ${ }^{3}$. Sin embargo, y en lo que aquí nos importa, parece imprescindible introducir algunos elementos que permitan entender el contexto en que se desarrolla la actualidad política y constitucional belga, así como los acontecimientos que, como antes apuntábamos, han llamado la atención internacional sobre la misma. De ahí que en los próximos epígrafes tratemos de esbozar, siquiera sea muy superficialmente, algunos de tales elementos, referidos a la evolución de la Constitución belga (1), a la peculiar configuración del federalismo en ella establecido (2), y, finalmente, al igualmente peculiar - proceso para la formación de Gobierno (3).

2 En realidad, Y. Leterme había presentado ya su renuncia en dos ocasiones anteriores, antes de llegar al acuerdo de gobierno. Por tanto, su renuncia — ya como Primer Ministro- era la tercera.

3 Así, en lengua francesa - que es la que el autor de estas líneas puede manejar- pueden citarse las obras de Francis DelpéréE (Le droit constitutionnel de la Belgique. Bruylant-LGDJ, Bruxelles-Paris, 2000) o de Marc UytTEndaele (Précis de droit constitutionnel Belge. Regards sur un système institutionnel paradoxal. Bruylant, Bruxelles, 2005 [3e éd.]). 


\section{La evolución de la Constitución Belga: Reformas del Estado y REFORMAS CONSTITUCIONALES}

Es bien sabido que Bélgica nació, como Estado independiente, en 1830, dotándose inmediatamente de una Constitución (aprobada el 7 de febrero de 1831) que se considera como una de las más progresistas de la época. De hecho, tal carácter avanzado se vio confirmado por una vigencia que se extendió, formalmente, hasta 1994, cuando el texto fue sustituido por el actualmente vigente.

De cualquier forma, la pervivencia de la Constitución no puede ocultar la existencia de unas vigorosas demandas de reforma constitucional, que produjeron una radical transformación del Estado. En efecto, en sus orígenes Bélgica se configuró como un Estado unitario, con el francés como única lengua oficial pese a la diversidad lingüística existente entre su población, que en su mayor parte hablaba diversas lenguas germánicas y romances. Ya a principios del siglo xx, tras la I Gran Guerra, Bélgica se convirtió en un Estado oficialmente trilingüe, reconociéndose carácter oficial, junto al francés, al holandés y al alemán.

De forma extremadamente sintética $-\mathrm{y}$ necesariamente simplista - cabría decir que la consolidación de este pluralismo cultural y su proyección política terminaron por provocar, en el último tercio del pasado siglo, cuatro profundas reformas constitucionales: son las llamadas "reformas del Estado", acaecidas en 1970, 1980, 1988-1989 y 1993, respectivamente. Tales reformas consagraron la existencia de tres Regiones (Valonia, Flandes y Bruselas) y de tres Comunidades culturales (francesa o valona, neerlandesa o flamenca y alemana o germanófona), cuyas competencias, muy limitadas al principio, se fueron ampliando progresivamente, a la vez que se les dotaba de una organización institucional propia, basada en órganos representativos directamente elegidos y en un Ejecutivo o Gobierno políticamente responsable ante los mismos ${ }^{4}$.

Tras esas cuatro grandes reformas, Bélgica quedó formalmente convertida en un Estado federal. Así lo refleja claramente el artículo 1 de su Constitución, cuyo clásico enunciado ("Bélgica está dividida en provincias") dejó paso, en 1993, al actualmente vigente: "Bélgica es un Estado federal, que se compone de comunidades y de regiones".

Todos estos cambios motivaron la aprobación de la Constitución actualmente vigente, publicada el 17 de febrero de 1994. De cualquier modo, cabe subrayar que - como acertadamente señalan, una vez más, las anotaciones de Mariano Daranas_ «se trata en rigor de un texto refundido de la

4 Sobre estas reformas, pueden verse las referencias incluidas en el portal oficial belgium.be (www.belgium.be); en castellano, véanse las esclarecedoras notas de Mariano Daranas a su traducción de la Constitución de Bélgica, en Francisco RUBIO LLORENTE y Mariano DARANAS PELÁEZ (eds.): Constituciones de los Estados de la Unión Europea. Barcelona, Ariel, 1997, especialmente página 113. En la medida de lo posible, las citas de la Constitución proceden de esta misma obra. 
Constitución originaria de 1831 y las numerosas reformas posteriores" ${ }^{5}$. Y que, a pesar de todo, la aprobación de este nuevo texto no puso fin a los anhelos —o tensiones - reformistas: de hecho, desde esta fecha la Constitución ha sufrido otras veintisiete reformas más (la primera, en marzo de 1996; las últimas, en mayo de 2007). Todo ello, al margen de otros cambios institucionales que han tenido lugar mediante leyes especiales, como las que el 13 de julio de 2001 permitieron la entrada en vigor de dos acuerdos políticos (los de Lambermont y Lombard), en los que se plasma la conocida como "quinta reforma del Estado", mediante la cual se transfirieron nuevas competencias a las Comunidades y Regiones y se modificó el funcionamiento de las instituciones de Bruselas ${ }^{6}$.

En definitiva, todos estos datos ilustran perfectamente la evolución acelerada - por no decir, la inestabilidad- de un régimen constitucional inicialmente unitario y tradicional, como es el belga. Un aspecto que resulta esencial para comprender las tensiones que, como ya se ha dicho, provoca $-\mathrm{O}$, por mejor decir, sigue provocando— el permanente debate sobre «la reforma del Estado".

\section{El PECUliar FEDERALismo BELGA}

Así las cosas, conviene desarrollar mínimamente algunos rasgos del peculiar régimen federal belga. Porque, si bien puede ser cierto que no existe un régimen federal típico, sino diferentes tipos de regímenes federales, no lo es menos que el caso belga suscita consideraciones absolutamente específicas ${ }^{7}$. Especialmente, porque — como también se ha apuntado con anterioridad, y recoge expresamente el citado artículo 1 de la Constitución- se trata de un régimen federal complejo, que no está simplemente basado en la existencia de Estados federados o miembros, sino en dos tipos de categorías: las comunidades y las regiones. La una, de base personal. La otra, de base territorial o geográfica.

La complejidad es aún mayor si se considera que, junto a las tres comunidades ("la comunidad francesa, la comunidad flamenca y la comunidad germanófona": artículo 2 C.B.) y las tres regiones ("la región valona, la región flamenca y la región de Bruselas": art. 3), existen "cuatro regiones lingüísticas: la región de lengua francesa, la región de lengua neerlandesa, la región bi-

5 Op. y loc. cit. Una circunstancia que explica la pervivencia de disposiciones claramente arcaicas, como las que prescriben que "el Poder Legislativo Federal será ejercido conjuntamente por el Rey, la Cámara de Representantes y el Senado"; o que "corresponde al Rey el Poder Ejecutivo Federal" (artículos 36 y 37, respectivamente; vide también el artículo 74).

6 Una completa referencia de cada una de las reformas constitucionales aprobadas desde la entrada en vigor del texto actualmente vigente puede encontrarse en la página web del Senado belga (www.senate.be/doc/const_fr.html).

7 A título de ejemplo, pueden verse las reflexiones de Julien PIERET ("La Belgique fédérale est-elle un Etat souverain?", en Revue Belge de Droit Constitutionnel, núm. 2007 [1], págs. 3-18). 
lingüe de Bruselas-Capital y la región de lengua alemana": art. 4). Si se considera, además, que "cada municipio del Reino formará parte de una de esas regiones lingüísticas" (artículo 4, párrafo 2). Si se considera, igualmente, que regiones y comunidades no tienen idéntica base territorial o geográfica: así, la comunidad germanófona se halla enclavada en la región valona; mientras que en la región de Bruselas Capital convive una mayoría francófona con una minoría flamenca. Y si se considera, por último, que los componentes esenciales de la federación (esto es, comunidades y regiones) están constitucionalmente dotados, cada uno de ellos, de un Parlamento y Gobierno propios (artículos 115,121 y 39).

De esta forma, el Estado federal belga — dejando al margen los vestigios de otras épocas históricas, a los que ya hemos aludido- ofrece un panorama institucional extremadamente complejo, en el que conviven instituciones federales, regionales y comunitarias (además de las provinciales y locales). Todas ellas se regulan en el Título III de la Constitución ("De los poderes"), el cual se abre con la afirmación constitucional — clásica desde 1831- de que "todos los poderes emanan de la Nación" ${ }^{8}$.

Y así, en el ámbito federal aparecen un Parlamento bicameral (formado por la Cámara de Representantes y el Senado), cuyos miembros «representan a la Nación, y no solamente a quienes los hayan elegido" (artículo 42; antiguo 32); y un ejecutivo formado por "El Rey y el Gobierno federal" (Título III, Capítulo III).

A continuación, el Capítulo IV ("De las comunidades y las regiones") dispone:

Por un lado, que «habrá un Parlamento de la Comunidad francesa y un Parlamento de la Comunidad flamenca, denominado Parlamento flamenco", así como «un Gobierno de la Comunidad francesa y un Gobierno de la Comunidad flamenca", cuya composición y funcionamiento se regularán mediante un tipo legislativo especial ${ }^{9}$. Junto a ellos, también "habrá un Parlamento [y un Gobierno] de la Comunidad germanófona cuya composición y funcionamiento" se regularán por ley ordinaria (artículos 115.1 y 121.1).

Y, por otro, que «los órganos regionales... comprenderán un Parlamento por cada Región" (115.2, en relación con el 39).

Todo ello, sin perjuicio de lo previsto en el artículo 137, que permite atribuir a los órganos de las comunidades el ejercicio de las competencias regionales. Una habilitación utilizada desde el primer momento por las instituciones flamencas, cuya fusión originó la existencia de un Parlamento y

8 Artículo 33 de la Constitución, que recoge literalmente el original artículo 25.

9 Se trata de unas leyes especiales, definidas en el último párrafo del artículo 4, cuya adopción exige la concurrencia de una doble mayoría: primero, "mayoría de votos de cada grupo lingüístico de cada una de las Cámaras", siempre que "esté presente la mayoría de los miembros de cada grupo" [lingüístico]; y, además, "que el total de los votos favorables en los dos grupos lingüísticos [flamenco y valón] alcance los dos tercios de los votos emitidos". Este tipo normativo es el llamado por la Constitución a desarrollar la mayor parte de sus disposiciones en materia de organización territorial del Estado belga. 
Gobierno únicos, simultáneamente regionales y comunitarios: la Comunidad flamenca ejerce de iure las competencias de la región de Flandes ${ }^{10}$.

Esta panorámica explica el que haya podido decirse que, si bien en Bélgica existen tres comunidades y tres regiones, "en Derecho constitucional belga, tres más tres no es siempre igual a seis». De hecho, los Parlamentos elegidos directamente son cuatro (los de las Regiones de Valonia y Bruselas-Capital y los de las Comunidades flamenca y germanófona); mientras que los órganos habilitados para dictar normas con valor de ley son siete (además de los cuatro Parlamentos citados, el de la Comunidad francesa, y las dos Asambleas de la Comisión Comunitaria francófona y de la Comisión Comunitaria Común de Bruselas) ${ }^{11}$.

Añádase a este complejo panorama otro dato adicional, como es el de la estricta distribución de competencias entre todos estos ámbitos: «la autoridad federal sólo tendrá competencias en las materias que le encomiendan expresamente la Constitución y las leyes que se dicten en virtud de ella. Las comunidades o las regiones, cada una en lo que les atañe, serán competentes en las demás materias en las condiciones y del modo que se determinen por ley" especial, aprobada según lo dispuesto en el último párrafo del artículo 4 (artículo 35). De este modo, y con las matizaciones que exige el caso de Bruselas (cuya población es bilingüe, por lo que tiene sus propias instituciones regionales, pero además participa en las instituciones de las Comunidades de pertenencia, francófona o flamenca), las tres comunidades, las tres regiones y el Estado federal «están en pie de igualdad y ejercen soberanamente sus competencias exclusivas bajo el régimen de equivalencia de sus normas" "2. En otras palabras, "el federalismo belga es paritario", ya que los diversos complejos orgánicos se hallan "en pie de igualdad" $\mathrm{y}$, desde un punto de vista normativo, "las leyes, adoptadas por el legislador central; los decretos, adoptados por los legisladores comunitarios y regionales; y las ordenanzas, adoptadas por el legislador de Bruselas, presentan la misma fuerza normativa. Entre todas estas normas, la igualdad es absoluta ${ }^{13}$.

\section{LA FORMACión DEL GOBIERNO FEDERAL}

En ese complejo marco institucional (y teniendo en cuenta asimismo la coherente evolución del sistema de partidos belga, al que nos referiremos más

10 La razón de que tal fusión no haya tenido lugar entre la Comunidad francesa y la Región Valona ha de buscarse, esencialmente, en la imposible superposición de la doble pertenencia, personal y geográfica, de la población francófona. En efecto, dada la mayoría francófona existente en la Región de Bruselas-Capital, la Comunidad francesa está formada no sólo por la población de la Región de Valonia (salvo la de los municipios pertenecientes a la región de lengua alemana, geográficamente enclavados como se dijo en Valonia), sino por la mayoría de la de Bruselas, que constituye además - lógicamente- un porcentaje muy alto del total de esta Comunidad.

11 M. UytTendaele, op. cit., pág. 904.

12 "Politique de la Belgique", en Wikipedia (http:/fr.wikipedia.org).

13 J. Pieret, op. cit., pág. 12. 
adelante), la formación de un Gobierno federal no resulta fácil. Tanto más cuanto el procedimiento para ello resulta, como mínimo, laborioso, debiendo someterse a diversas reglas expresamente previstas en la Constitución y a prácticas políticas generalmente respetadas, y que en ocasiones resultan, como mínimo, sorprendentes.

\section{A) Reglas constitucionales}

En este punto, cabe decir que la Constitución — reflejando así su ya comentado arraigo tradicional- es, en principio, somera. Según su artículo 96 (que reproduce, literalmente, el artículo 65 del texto de 1831) «El Rey nombra y revoca a sus Ministros".

Este poder de nombramiento (matizado por un apartado segundo que se introdujo en 1993 y que prevé el supuesto de pérdida de confianza parlamentaria del Primer Ministro) se ve, ciertamente, sometido a ciertas condiciones, a veces tradicionales —-más o menos adaptadas-, y otras más recientes. Así, por ejemplo, entre las primeras han de citarse aquellas según las cuales "sólo los belgas podrán ser Ministros", excluyéndose a todos los miembros de la familia real ${ }^{14}$. Mientras que las segundas incluyen la que prescribe que «el Consejo de Ministros contará con quince miembros como máximo" (artículo 99, párrafo $\left.1^{\mathrm{o} 15}\right)$; o las que prevén que "con excepción, en su caso, del Primer Ministro... contará con tantos miembros de expresión francesa como de expresión neerlandesa" (99, párr. 2\%); o que "cuente con personas de diferente sexo" (artículo 11 bis $^{16}$ ).

De cualquier modo, y al margen de esas condiciones, lo cierto es que la fórmula adoptada por el artículo 96 de la Constitución otorga al Rey un poder de considerable amplitud. Como se ha subrayado, "la autoridad investida por la Constitución de la responsabilidad de designar a los Ministros es, indiscutiblemente, el Rey. Él, y sólo él, tiene derecho a nombrarlos", actuando "como autoridad perteneciente al poder ejecutivo federal, en el sentido del artículo 37 C." ${ }^{17}$.

Tales reglas no son particularmente llamativas, al menos en su formulación sobre el papel. No obstante, lo cierto es que plantean también algunas cuestiones discutibles. Porque, por expresarlo en los términos de un comentario al texto constitucional belga anterior a su refundición (y, recordémoslo, no modificado en este punto), dicha regla "reserva al Rey [actuando con el correspondiente refrendo] la posibilidad de componer los Gobiernos, de aceptar $y$ de rechazar su dimisión, de designar a los Ministros, de aceptar y de re-

14 Artículos 97 y 98 C.B., que recogen — con algún matiz, en el primer caso— los anteriores artículos 86 y 87, intactos desde 1831.

15 Previsión calificada por M. DARANAS como "completamente nueva y excepcional en el Derecho comparado" (op. cit., pág. 125).

16 Artículo introducido por la reforma de 21 de febrero de 2002.

17 F. Delpérée, Le droit constitutionnel..., cit., págs. 410-411. También M. UytTendaele destaca que «en las fases de formación de Gobierno... el Rey dispone de un margen de maniobra mucho más importante que el que se le reserva habitualmente" (Précis..., cit., pág. 416). 
chazar su dimisión individual, de destituirlos" ${ }^{18}$. Lo cual, especialmente en lo referido a la posibilidad de rechazar una renuncia, no deja de suscitar alguna sorpresa, reiterada en los acontecimientos del último año, que han demostrado su actual vigencia.

En todo caso, es evidente que estas reglas constitucionales expresas deben completarse con otras implícitas en el sistema. Entre ellas, debe mencionarse en primer lugar algo que parece obvio, como es el hecho de que en un sistema parlamentario, el Gobierno debe gozar de la confianza de las Cámaras (algo expresamente recogido ahora por la regulación de la moción de censura y de la cuestión de confianza en el artículo 96, párr. $2^{\circ}$ C.B.). Aunque, posiblemente por los antecedentes existentes en Bélgica, la regla de que la nominación del Gobierno no "está sometida al asentimiento o a la ratificación de las Cámaras legislativas" abre la puerta a consideraciones sobre la posibilidad de "Gobiernos minoritarios". Así, se ha señalado que "la confianza o desconfianza de la[s] Cámara[s]... no se presume, se verifica". Por tanto, "nada impide al Rey componer un Gobierno que no goce de un respaldo suficiente de diputados... Este Gobierno tendrá entonces su oportunidad", si bien la expresa negación de la confianza parlamentaria provocará inevitablemente la caída del mismo ${ }^{19}$.

Y, junto a tales reglas expresas o tácitas, la formación del Gobierno federal belga se ajusta a otras prácticas que han sido convencionalmente asumidas, conformando un auténtico "ritual ${ }^{20}$ que inmediatamente pasamos a examinar.

B) Prácticas políticas

Es preciso insistir en que se habla aquí de prácticas dirigidas a facilitar la elección regia, en las que no cabe apreciar la existencia de una auténtica "convención constitucional, sino simplemente una práctica que se recomienda, por regla general" y por razones de utilidad, "respetar" ${ }^{21}$. Y que afectan a un período en el cual «el Rey desempeña un papel determinante. Éste es el único momento en el que está en condiciones de influir directamente sobre la vida política nacional, independientemente de la voluntad del Gobierno. En esta ocasión, él elige las personas encargadas de llevar a cabo las negociaciones relativas a la formación del Gobierno. Estas designaciones son anunciadas por un comunicado de palacio, y no constituyen el objeto de un acto refrendado por un ministro, al menos en el momento en que se deciden. Pese a lo cual, formalmente, los ministros dimisionarios asumen la responsabilidad política de las mismas" ${ }^{22}$.

El proceso se inicia al día siguiente de las elecciones generales federales, cuando el Primer Ministro presenta al Rey la dimisión de su Gobierno, siendo

18 F. DelPÉRÉE y François Jongen, Quelle revisión constitutionnelle? Louvain-la-NeuveBruxelles, Academia-Bruylant, 1987, pág. 113 (las cursivas han sido añadidas).

19 F. Delpérée, Le droit constitutionnel..., cit., págs. 411 y 414-415.

20 F. Delpérée, op.cit., citando a A. Molitor, a quien sigue en su descripción del proceso (págs. 420-423). Vide también M. UytTendaele, op. cit., págs. 417 y ss. Una breve exposición de estas prácticas puede encontrarse, asimismo, en el citado portal oficial belgium.be.

21 F. DelpérÉE, ob. cit., pág. 420.

22 M. UytTendaele, ob. cit., pág. 417. 
encargado de seguir en funciones hasta la formación de otro nuevo. Se abre, a continuación, un período de consultas, presidido por el principio de que «el Rey es libre" en las mismas, pero durante el cual el Rey recibe — —Según la tradición protocolaria - a diversas personalidades, como el Primer Ministro dimisionario, los Presidentes de ambas Cámaras, los líderes de los principales partidos del país, así como a los responsables de organizaciones económicas y profesionales ${ }^{23}$.

Tras estas consultas, el Rey puede optar por designar a un formador (formateur), encargándole directamente la formación de un nuevo Gobierno. Sin embargo, más frecuentemente, y debido a la falta de mayorías claras, se ve impulsado a desarrollar algunos pasos intermedios, lo que suele traducirse en la designación de un informador (informateur). Éste, cuya designación tampoco es absolutamente libre y ha de tener en cuenta los condicionantes existentes en cada momento, suele ser un responsable político experimentado encargado de profundizar en la labor "exploratoria" iniciada por el Jefe del Estado. A tal fin debe examinar "todas las fórmulas de gobierno posibles", remitiendo al Rey su informe, que puede consistir en "un documento escrito que sintetiza sus conversaciones", aconsejándole en su caso sobre la designación de un formador.

Ahora bien: en caso necesario - esto es, cuando la crisis se complica- el Rey puede llamar, en una tercera fase, a uno o varios mediadores (médiateurs), cuya misión está a medio camino entre la mera información y el impulso para aproximar posturas. Es más: también está prevista la designación de un negociador (négociateur), abiertamente orientado a posibilitar acuerdos sobre puntos concretos.

En caso de tener éxito, en uno u otro momento, el proceso finaliza pues con la designación de un formador, que normalmente se convertirá en el nuevo Primer Ministro (aunque la práctica política ofrezca algunas excepciones, en las que esta figura ha debido dejar paso, en el último momento y por razones diversas, a otro líder). Lo cual no implica que todo esté hecho: el formador debe establecer, en primer lugar, una fórmula de coalición; a continuación, un programa de gobierno; y, finalmente, un equipo para llevarlo a cabo. Todo lo cual exige "procedimientos a menudo largos y laboriosos", y "cada vez más formalizados" ${ }^{24}$.

\section{LOS "JUGADORES»: EL SISTEMA DE PARTIDOS Y LA NECESARIA BÚSQUEDA DE COALICIONES}

Evidentemente, y como ocurre sin excepción en todos los regímenes políticos, el funcionamiento de todos los elementos hasta aquí observados se ve

23 Este mismo autor subraya que, desde 1991 y en uso de su libertad de organizar sus consultas, ni Balduino I ni Alberto II han recibido a los representantes de los partidos radicales e independentistas (Front National, Vlaams Blok o Vlaams Belang: pág. 417).

24 F. Delpérée, op. cit., pág. 422. 
condicionado por el sistema de partidos existente en Bélgica, y las relaciones entre los mismos. Y, a estas alturas, difícilmente podrá extrañar la afirmación de que cualquier aproximación a esta materia debe partir del hecho, ya recogido, de la consolidación de un pluralismo social que adquiere inmediata, y poderosa, proyección política e institucional, hasta el punto de impulsar las sucesivas "reformas del Estado".

De esta manera, cabe señalar que la historia política belga, como la de otros muchos países europeos, muestra, hasta la segunda mitad del siglo xx, el dominio de unos partidos que se corresponden con las principales corrientes ideológicas existentes en el continente. En efecto, durante el siglo XIX las principales fuerzas políticas eran Católicos y Liberales, a los que se unieron, desde la década de los ochenta, los Socialistas. Sin perjuicio de la existencia de otros partidos, como los Rexistas (en los años treinta), los Comunistas (que alcanzaron relativa importancia y llegaron a participar en algunos Gobiernos entre 1944 y 1947, para ahogarse prácticamente durante la "guerra fría"), o los verdes (que adquieren peso en la última década del siglo $\mathrm{xx}$ ) estas tres grandes corrientes dominaron el panorama político hasta la década de 1960. Y de esta forma, los partidos democristiano (tras la II Guerra Mundial, organizado como PSC/CVP), socialista (PSB/BSP) y liberal (PVV/PLP) constituyeron durante todo este tiempo Gobiernos, ya monocolores (esencialmente, democristianos) o ya, más frecuentemente, de coalición, según fórmulas diversas.

Sin embargo, el proceso de diferenciación etno-lingüística entre flamencos y valones determinó que esos tres grandes partidos se escindieran, además de permitir el auge de grupos — generalmente minoritarios, pero en absoluto marginales- específicamente vinculados a una de las comunidades. En definitiva, en línea con la evolución del Estado, el sistema de partidos belga resulta hoy, en gran parte, de una mera yuxtaposición de dos subsistemas distintos, el francófono y el flamenco. Ello, unido a un sistema electoral proporcional, se ha traducido en una creciente dificultad para conseguir mayorías de gobierno, que en las últimas décadas suelen exigir del concurso de cinco, seis o más partidos ${ }^{25}$.

De este modo, las últimas elecciones legislativas de 10 de junio de 2007 determinaron la distribución de los 150 escaños de la Cámara de Representantes entre once formaciones políticas ${ }^{26}$, la mayor de las cuales (a su vez, una

25 Pese a su indiscutible interés jurídico y constitucional, dejamos al margen otros aspectos del régimen electoral belga, como por ejemplo lo relativo al carácter obligatorio del sufragio (artículos 62 y 68.3 C.B.).

26 Dado el propósito de este epígrafe, dirigido a presentar a los diferentes actores políticos belgas, no prestaremos tampoco especial atención aquí al Senado. Baste señalar ahora que los 40 senadores elegidos directamente el 10 de junio también representaban a las mismas once formaciones. Y que a ellos han de unirse otros 34 senadores: 21 designados por los Parlamentos de las Comunidades, 10 cooptados por los propios senadores, y los senadores de iure (actualmente, tres): "Los hijos del Rey o, en su defecto, los descendientes belgas de la rama de la familia real llamada a reinar, serán senadores natos al cumplir los dieciocho años de edad, si bien no podrán votar hasta cumplir los veintiún años, y no serán contados para el cómputo del quórum de asistencia" (artículo 72 C.B.). 
coalición electoral formada por democristianos flamencos y un grupo nacionalista, Nueva Alianza Flamenca: C-D\&V-N-VA) logró apenas un 18'5 \% de los votos. Las otras diez listas representadas obtuvieron tan sólo entre un 12'5 \% y un 1'97 \%, lo que da idea de —en un sistema altamente proporcional- la dificultad de reunir mayorías absolutas.

En definitiva, en la Cámara no hay ningún partido de ámbito estrictamente nacional belga: sólo están presentes seis partidos flamencos ${ }^{27}$, y cinco francófonos ${ }^{28}$, cada uno de los cuales reúne apoyos casi exclusivamente procedentes de su comunidad lingüística ${ }^{29}$. Un panorama que se revela poco halagüeño a la hora de reflexionar sobre la evolución futura del sistema belga.

\section{APUNTES SOBRE UNA CRISIS}

Porque, en efecto, la atomización política y la profunda división existente entre partidos flamencos y partidos francófonos (cada uno de los cuales tiene un electorado propio y definido en términos lingüísticos, que en el caso flamenco coinciden también sustancialmente con los geográficos) explican algunos de los elementos más determinantes a la hora de formar Gobierno, y que por lo tanto han contribuido a llamar la atención sobre la duración de la crisis.

Porque, como ya quedó apuntado en la introducción a estas páginas, la trabajosa consecución de un acuerdo de gobierno suscitó, desde el principio, serias dudas, especialmente — ¿cabe dudarlo? - por las diferencias existentes entre partidos francófonos y flamencos en torno a... la reforma del Estado.

De esta forma, tras las elecciones de junio el Rey Alberto II nombró como informador al líder de los liberales francófonos, Didier Reynders, ministro de Finanzas en el saliente Gobierno encabezado por el liberal flamenco Guy Verhofstadt. El cual remitió su informe el 4 de julio siguiente, señalando que «la constitución de una coalición depende de un acuerdo sobre la reforma institucional ${ }^{30}$. A continuación, y de acuerdo con el ritual anteriormente observado, el Rey nombró mediador a Jean-Luc Dehaene, democristiano flamenco y antiguo Primer Ministro de Bélgica (1992-1999), confiándole una "misión de mediación y negociación", y cuyas conclusiones fueron similares, apuntando a

27 A la citada coalición C-D\&V-N-VA (18'5 \%), han de unirse: el Vlaams Belang ("Interés flamenco", resultado de la reconversión del "Bloque Flamenco", prohibido por la justicia belga en 2004, y considerado como un grupo "de extrema derecha xenófoba": P. ASTIÉ, D. BREILLAT et C. LAGEOT, "Repères étrangers", en Pouvoirs, núm. 123 [2007], pág. 160): 12’0 \%; el Open VLD (liberal): 11 '8 \%; el SP-a— spirit (socialista): 10'26\%; la "lista Dedecker" (nacionalista): 4'03; y Groen! (ecologistas): 4’0\%..

28 Los liberales del Mouvement réformateur (12'5 \%), el Parti Socialiste (10'86 \%), el Centre Démocrate Humaniste (6'06 \%), los ecologistas de Écolo (5'1\%), y el Front National (1'97 \%).

29 En conjunto, y respondiendo básicamente a la distribución de la población belga, el conjunto de los partidos flamencos recibió cerca de un $60 \%$ de los votos válidos emitidos, frente al poco más del $36 \%$ de las papeletas a favor de los partidos francófonos.. pág. 160

30 Cfr. P. Astié, D. Breillat et C. LAGEOT, "Repères étrangers", en Pouvoirs, 124 (2008), 
una coalición entre democristianos y liberales (que lograron reunir cerca del $49 \%$ de los votos emitidos, consiguiendo 81 de los 150 escaños de la Cámara baja).

Así las cosas, el Rey designó como formador de Gobierno a Yves Leterme (líder de los democristianos flamencos, y Ministro-Presidente de Flandes), cuyo programa preveía "una reforma del Estado federal a favor de Flandes", así como la división de un distrito electoral histórico (existente desde la revolución de 1830), el de Bruxelles-Hal-Vilvorde (BHV).

Este distrito resulta absolutamente excepcional, ya que comprende 54 municipios repartidos por el territorio de dos Regiones (Flandes y Bruselas): monolingüe la una, bilingüe la otra; de carácter esencialmente rural, la primera; y fuertemente urbana, la segunda... Por estas circunstancias, sus habitantes (francófonos unos, flamencos otros) pueden votar en todo el distrito -incluyendo, pues, las zonas flamencas - por listas francófonas. Algo, además, que ha sido declarado contrario al principio de igualdad (en cuanto que otorga a los francófonos residentes en la parte de este distrito situada en la región de Flandes unos derechos lingüísticos y políticos que no tienen los flamencos que residen en la región Valona), y que se complica aún más por otros datos, que no procede recoger ahora

En este contexto, todos los partidos flamencos persiguen dividir el distrito, a fin de segregar a la zona neerlandófona. Y los francófonos se oponen frontalmente, entre otras cosas porque la población de habla francesa residente en los municipios de Hal-Vilvorde (muchos de los cuales son oficialmente monolingües) perderían su actual derecho a utilizar su propia lengua ${ }^{31}$. Pero no cabe augurar una decisión impuesta por la mayoría flamenca, ya que la decisión se inscribe en el ámbito de las competencias federales, donde opera el artículo 54 de la Constitución, que otorga un auténtico "derecho de veto suspensivo" a cada grupo lingüístico.

En efecto, según dicho precepto «una moción motivada, firmada al menos por las tres cuartas partes de los miembros de uno de los grupos lingüísticos y presentada tras la aprobación en Comisión, y antes de la votación en sesión plenaria, puede declarar que las disposiciones de un proyecto o proposición de ley... son susceptibles de afectar gravemente a las relaciones entre las comunidades. En tal caso, se suspenderá el proceso parlamentario y la moción se remitirá al Consejo de Ministros que, en un plazo de treinta días, emitirá su

31 Véase, a este respecto, la reveladora noticia según la cual el alcalde del municipio neerlandófono de Zaventem, en Hal-Vilvorde, habría dictado y difundido una circular — distribuida "en todos los buzones", en "holandés, francés, inglés, alemán, español y árabe»— según la cual "el municipio... está situado en la parte neerlandófona de Bélgica. [La legislación] prohíbe formalmente a sus empleados utilizar una lengua distinta del neerlandés con los administrados. Si usted no utiliza correctamente el neerlandés [si vous n'êtes pas assez bon en néerlandais], le rogamos que acuda con un intérprete" (en la página web de Le soir: www.lesoir.be, 30 de julio de 2008). De hecho, el sentido esencialmente simbólico de esta reivindicación flamenca radica en que confirmaría el carácter monolingüe de toda la Región de Flandes, forzando a los francófonos que en ella residan a integrarse en términos lingüísticos. 
opinión motivada sobre la moción e invitará a la Cámara que esté conociendo del asunto a pronunciarse sobre la misma, o bien sobre el proyecto o la proposición de ley eventualmente enmendados". Ciertamente, este mecanismo sólo puede utilizarse una vez por los miembros de un grupo lingüístico respecto a una misma propuesta, pero sus efectos políticos podrían ser devastadores, en la medida en que la minoría valona podría forzar que el asunto pasase a manos del Gobierno (recuérdese, paritario entre flamencos y valones), haciendo así casi imposible un acuerdo.

Volviendo al desarrollo de la crisis gubernamental, lo cierto es que las posiciones flamencas y francófonas (y, por tanto, de los partidos democristianos y liberales de ambas comunidades) resultaban inconciliables, por lo que el 17 de agosto el Rey decidió "suspender" el encargo confiado a Leterme como formador. Dos días después, le encargó nuevamente iniciar "nuevos contactos", pero el intento se mostró infructuoso dos días más tarde. Por lo cual, el 30 del mismo mes el Rey encargó al Presidente de la Cámara de Representantes, el también democristiano flamenco Herman Van Rompuy, que asumiese una mission d'exploration, inaugurando así una nueva categoría que añadir a las ya conocidas. El clima de crisis provocó algunas iniciativas (en particular, la firma de manifiestos y algunas manifestaciones populares, esencialmente en Bruselas, donde se llamó a la población para colgar banderas belgas en sus balcones y ventanas). Y el 29 de septiembre, el Rey encargó a Leterme, por tercera vez, la formación de Gobierno...

Hasta este momento, el record de duración en este proceso era de 148 días, tiempo que necesitó, en 1988, la formación del Gobierno Maertens VIII. Como ya se ha dicho, este plazo ha sido ampliamente superado, atravesando otras vicisitudes (nueva renuncia de Y. Leterme en diciembre de 2007; acuerdo para formar un "Gobierno interino", encabezado por el Primer Ministro en funciones, G. Verhofstadt, por un período de tres meses; nuevas rondas de negociaciones, mediaciones...). Finalmente, y tras 282 días, se anunció la firma de un acuerdo de Gobierno pentapartito, formado por democristianos flamencos ( $\sin$ su socio nacionalista, que se negó a unirse a esta coalición) y valones, liberales de ambas Comunidades, y - la relativa sorpresa- los socialistas francófonos, cuya presencia rompía con la paridad de fuerzas tradicional en Bélgica... De esta forma, un comunicado de palacio fechado el 20 de marzo señalaba que «el Rey ha recibido en audiencia esta mañana, en el Castillo de Laeken, al Primer Ministro, Señor Guy Verhofstadt. El Rey ha aceptado la dimisión del Señor Verhofstadt de sus funciones de Primer Ministro y, a propuesta del mismo, ha nombrado Primer Ministro al Señor Yves Leterme „32. En todo caso, el acuerdo de gobierno parecía, desde sus inicios, destinado a agotarse en el verano, fecha límite que los partidos flamencos habían fijado a los francófonos para llegar a acuerdos sobre la reforma del Estado, o la reforma institucional ${ }^{33}$.

32 Recogido en belgium.be.

33 Vide El País, 14 y 15 de julio de 2008, que la considera "el auténtico conflicto en el que se encuentra enzarzado el país". 
Y así ha sido. La imposibilidad de llegar a acuerdos en esta materia, en la atribución de nuevas competencias a las Comunidades y Regiones perseguida por los flamencos; en torno a la situación del distrito de Bruselas-Hal-Vilvorde... Todo ello ha provocado la nueva renuncia de Leterme (quien, dicho sea de paso, ha sido hospitalizado en varias ocasiones durante el año transcurrido desde que fue nombrado formador).

Ahora bien: como se ha destacado anteriormente, y en una sucesión de acontecimientos que han retrasado notablemente el cierre de estas páginas, el Rey, tras celebrar diversas consultas, ha decidido no admitir la renuncia del Primer Ministro. En efecto, según un comunicado de palacio hecho público el día 17 de julio, "el Rey ha rechazado la dimisión del Gobierno, y le ha pedido que promueva al máximo las oportunidades de diálogo" institucional. Para lo cual, ha optado también por encargar a tres personalidades la misión de «examinar de qué manera pueden ofrecerse garantías para entablar de manera creíble" este diálogo ${ }^{34}$.

En esta ocasión, ninguna de esas tres personalidades es flamenca: son un diputado liberal de Bruselas, francófono (François-Xavier de Donnea), un eurodiputado centrista, igualmente valón (Raymond Langendries) y el Ministro-Presidente de la pequeña comunidad germanófona, el socialista KarlHeinz Lambertz. Su misión es la de preparar el terreno para la "reforma del Estado". Y su llamativa extracción - concretamente, la ausencia de miembros flamencos- se explica, según los medios de comunicación, porque el partido de Leterme (que, recuérdese, es el mayoritario en Bélgica, y por lo tanto una referencia inexcusable a la hora de formar mayorías) habría exigido que, en esta ocasión, sean los francófonos quienes deban plantear iniciativas para el reiterado "diálogo institucional". Se trataría, en otras palabras, de que la minoría francófona convenza a la mayoría flamenca de su voluntad de iniciar un diálogo "sin límites" (sans tabou) 35 .

En el momento de cerrar estas páginas, ésa es la situación. Los mediadores parecen haber constatado "la existencia de un consenso para abordar una reforma del Estado en profundidad", y se han inclinado por incluir en el diálogo institucional dirigido al efecto a representantes de las entidades federadas, en particular de las tres regiones y de la comunidad germanófona ${ }^{36}$, lo cual daría aire al Gobierno para seguir gobernando y gestionando otras materias económicas y sociales sobre las que sí existe acuerdo.

Mientras tanto, las fuerzas centrífugas siguen operando, y no sólo en Flandes: según un reciente sondeo, el 49 por ciento de los belgas francófonos son favorables a vincularse a Francia, en caso de ruptura del Estado belga. Algo que encontraría buena acogida en el 60 por ciento de los franceses... ${ }^{37}$.

34 Las citas proceden de la información ofrecida por Le Monde.fr y Libération.fr, los días 17 y 18 de julio.

35 Libération.fr, citando al portal de La Libre Belgique.

36 www.laLibre.be, 31 de julio de 2008.

37 Sondeo realizado por Ifop para los diarios Le Soir (belga) y La Voix $d u$ Nord (francés), citado en www.lesoir.be. 
Todo ello cuestiona directamente la divisa "la unión hace la fuerza", que, según el artículo 193 de la Constitución de Bélgica, integra el escudo del Reino. Pero el futuro no está escrito... En todo caso, su evolución podrá reflejarse en futuras crónicas.

Aвstract.- After the Belgium general elections, held in june 2007, nine months were needed to reach a political agreement to form a governmental majority. After four months more, the Prime Minister was forced to resign, altbough his resignation was not accepted by the king. The paper deals with the causes of this political and institutional crisis, briefly describing the recent constitutional evolution of Belgium, the constitutional procedures and the political context, and so trying to provide for some data that may belp to understand all these developments. 